\title{
Deep Cerebral Venous Thrombosis: An Illustrative Case with Reversible Diencephalic Dysfunction
}

\author{
David J. Gladstone, Frank L. Silver, Robert A. Willinsky, Felix J. Tyndel, \\ Richard Wennberg
}

\begin{abstract}
Background: Isolated thrombosis of the deep cerebral veins is rare and its diagnosis can be difficult. Mortality is often high and little is known about the long-term prognosis. Case report: We report a 24-year-old woman with akinetic mutism and extensive bilateral thalamic lesions. CT and MRI allowed early diagnosis by demonstrating thrombosis within the internal cerebral veins, without the need for angiography. Heparin treatment was used safely despite the presence of thalamic and intraventricular hemorrhage. After five weeks, the patient recovered rapidly and remains well at 18 months. Serial MRI showed dramatic resolution of the imaging abnormalities. Conclusions: The clinical features and characteristic neuroimaging appearance of deep cerebral venous thrombosis should be recognized by physicians caring for stroke patients. Deep cerebral venous thrombosis can produce extensive venous congestion and vasogenic edema without early infarction. Excellent clinical recovery is possible even after severe and prolonged neurological deficits.
\end{abstract}

\begin{abstract}
RÉSUMÉ: Thrombose veineuse cérébrale profonde: un cas type présentant une dysfonction diencéphalique réversible. Introduction: La thrombose isolée de veines cérébrales profondes est rare et son diagnostic peut être difficile. La mortalité est souvent élevée et on connaît mal le pronostic à long terme. Étude de cas: Nous rapportons le cas d'une femme de 24 ans ayant présenté un mutisme akinétique et des lésions thalamiques bilatérales étendues. Le CT scan et la résonance magnétique ont permis de poser le diagnostic d'emblée en démontrant une thrombose dans les veines cérébrales internes, sans recourir à l'angiographie. Le traitement à l'héparine a été utilisé sans complication malgré la présence d'hémorragies thalamiques et intraventriculaires. Cinq semaines après l'événement, la patiente avait récupéré et son état était bon 18 mois plus tard. Des examens répétés par résonance magnétique ont montré une résolution dramatique des anomalies observées initialement. Conclusions: Les manifestations cliniques et les images neuroradiologiques caractéristiques de la thrombose veineuse cérébrale profonde devraient être connues des médecins qui traitent des patients atteints d'accidents vasculaires cérébraux. Une thrombose veineuse cérébrale profonde peut provoquer une congestion veineuse étendue et un oedème vasogénique sans infarcissement précoce. Une excellente récupération clinique est possible même si le patient présente des déficits neurologiques sévères et prolongés.
\end{abstract}

Can. J. Neurol. Sci. 2001; 28: 159-163

Rapid and accurate diagnosis of stroke is essential because of the increasing availability of acute treatment options. Clinicians caring for stroke patients need to be familiar not only with the common arterial stroke syndromes, but also with early recognition and management of cerebral venous thrombosis (CVT). Cerebral venous thrombosis can involve the dural sinuses, superficial cortical veins, or deep venous system, either alone or in combination. ${ }^{1}$ Deep cerebral venous thrombosis (DCVT) is the least common form of CVT, with only about 60 reported cases. Deep cerebral venous thrombosis can present as an acute neurological emergency with life-threatening bilateral destruction of thalamus, basal ganglia, and subcortical white matter. This paper illustrates the clinical and neuroimaging features that allow early diagnosis, and emphasizes that excellent recovery is possible despite prolonged diencephalic dysfunction.

\section{CASe Report}

A previously healthy 24-year-old student was admitted to the intensive care unit in an akinetic mute state. She was found "catatonic" on her apartment floor after family could not contact her for three days. She had been well until one week earlier, when she developed severe

From the University of Toronto and the Royal College of Physicians and Surgeons of Canada Clinician-Investigator Program (DJG); Division of Neurology, University Health Network (FLS, FJT, RW); University Health Network Stroke Program (FLS);

Division of Neuroradiology, University Health Network (RAW); Division of Neurology, The Scarborough Hospital (RW), Toronto, Ontario, Canada ReCEIVEd October 13, 2000. ACCEPTED In FINAL FORM MARCh 20, 2001. Reprint requests to: David J. Gladstone, Cognitive Neurology Unit, Room A421, Sunnybrook and Women's College Health Sciences Centre, 2075 Bayview Avenue, Toronto, Ontario M4N 3M5 Canada 
headache, nausea, and vomiting. Her only medication was the oral contraceptive pill. Examination revealed temperature $37.9^{\circ} \mathrm{C}$, pressure sores on the skin, and mild meningismus. She was awake but mute. She had minimal spontaneous movement, flat affect, and followed only simple commands. There was bilateral facial weakness and asymmetric quadriparesis (grade 3-4/5) with hyperreflexia and extensor plantar responses. Pupils were reactive to light $(4 \mathrm{~mm})$. There was no papilledema. There was impaired upward gaze and an abduction palsy of the left eye.

White blood cell count was $12 \times 10^{9} / \mathrm{L}$ (normal 4-11). Other routine laboratory studies, drug screen, pregnancy test, and chest $\mathrm{x}$-ray were negative. Brain computed tomography (CT) (Figure 1) revealed mild symmetric bilateral hypodensity in the thalamus and basal ganglia, initially interpreted as carbon monoxide poisoning. Further neuroradiological interpretation revealed increased density within the deep cerebral veins, and a small amount of blood in the right occipital horn. CSF showed xanthochromia, elevated RBC (1600) and WBC (35), normal glucose (3.9), and increased protein (1.9 g). Initial management consisted of ceftriaxone, ampicillin, and acyclovir for possible central nervous system infection, as well as neurosurgical consultation, after which nimodipine was given for possible subarachnoid hemorrhage with vasospasm. Cultures of blood, urine, and CSF were negative. Brain magnetic resonance imaging (MRI) the next day revealed extensive signal abnormalities within the thalamus and basal ganglia bilaterally (Figure 2a), accompanied by hyperintense signal on T1-weighted images in the internal cerebral veins, vein of Galen, and straight sinus, diagnostic of thrombosis of the deep venous system. Superior sagittal and lateral sinuses were patent on magnetic resonance venography. Anticoagulation with intravenous heparin was initiated. MRI one week later showed asymptomatic hemorrhagic transformation within the thalamus bilaterally.

She remained in an abulic, amnestic state with periods of agitation and psychosis. Despite the severity of imaging abnormalities, a rapid recovery of function began after five weeks, coinciding with recovery from her anterograde amnesia. MRI at two months revealed recanalization of the vein of Galen, straight sinus, and one of the internal cerebral veins, and dramatic reduction in the thalamic lesions. She continued to improve, and achieved full functional recovery with return to university classes and office work. At four months, neurological examination was normal except for mild impairment of recent memory. Hematological investigations identified protein $\mathrm{C}$ deficiency. She remains on long-term oral anticoagulation, off the oral contraceptive pill, and free of recurrent thrombotic events. At 18 months, MRI shows almost complete resolution of the lesions except for two small residual foci of abnormal signal within the thalami suggesting infarction (Figure $2 b$ ).

\section{Discussion}

Deep cerebral venous thrombosis is a treatable, often lifethreatening, neurological emergency. It should be considered in the differential diagnosis of unexplained coma, akinetic mutism, abulia, and bilateral thalamic lesions. DCVT can masquerade as subarachnoid hemorrhage, meningitis, encephalitis, and basilar artery territory infarction. Our patient's presentation initially suggested aneurysmal subarachnoid hemorrhage, with headache, meningismus, and blood on CT and in the CSF.

Compared to dural sinus thrombosis, DCVT is rare (nine out of 135 cases in the largest series of CVT), has a higher mortality, and is more likely to present acutely with impaired conscious-

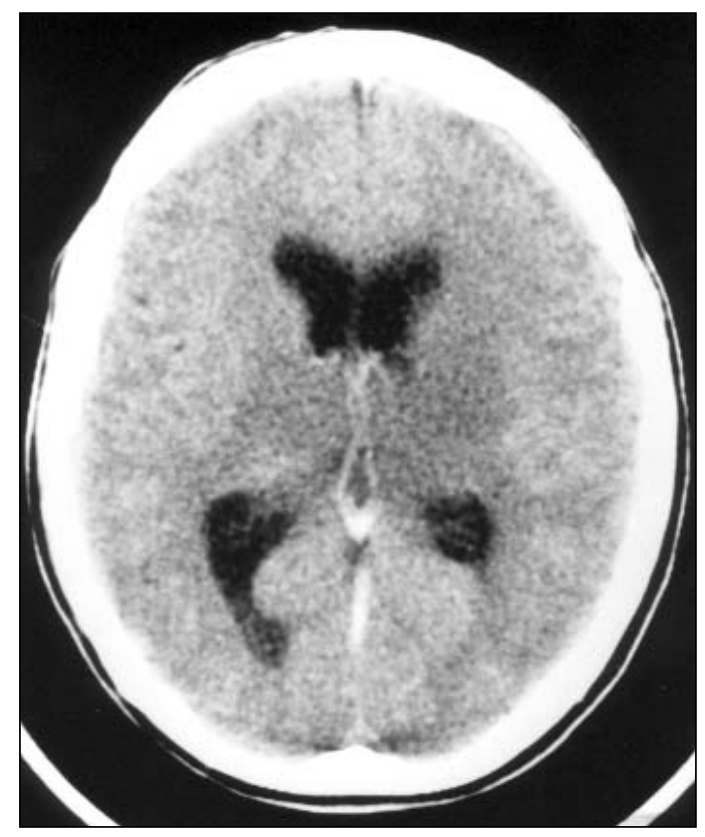

Figure 1: Noncontrast axial CT scan from a patient with deep cerebral venous thrombosis. Note the bilateral hypodensities in the thalami and left corona radiata, and increased density in the internal cerebral veins and vein of Galen.

ness and long tract signs. ${ }^{1,2}$ In a retrospective review of 49 patients with DCVT, the presenting features were confusion, coma, or mental status changes $(76 \%)$; headache $(63 \%)$; nausea and/or vomiting (41\%); hemiparesis (33\%); seizure (14\%); fever $(12 \%)$; papilledema (10\%); and aphasia $(6 \%){ }^{2}$ Residual memory impairment due to thalamic involvement has been described and was present in our patient. ${ }^{3}$ The CSF is often abnormal with RBC in two-thirds of patients, pleocytosis in one-third, and increased protein. ${ }^{1}$ Milder forms of DCVT with a favourable prognosis are being increasingly recognized with MRI.,4

The typical imaging findings of DCVT may be evident on CT and confirmed by MRI (Figures 1 and 2). On noncontrast CT a hyperdense "cord sign" in the diencephalic region indicates acute thrombosis within the internal cerebral veins, vein of Galen, or straight sinus; bilateral symmetric hypodensity within the thalamus, basal ganglia, and corona radiata represents edema or infarction. ${ }^{5}$ MRI confirms the diagnosis by demonstrating clot in the deep cerebral veins. ${ }^{6}$ The pattern of edema, which is clearly evident on MRI, distinguishes venous infarcts from arterial occlusive disease. Hemorrhagic transformation of the ischemic tissue may be evident. Serial MRI studies can monitor clot extension or recanalization. ${ }^{7}$ With MRI, conventional angiography is now seldom necessary for diagnosis. Recent reports suggest diffusion- and perfusion-weighted MRI, or magnetic resonance spectroscopy, may add prognostic information in the acute stage by distinguishing reversible vasogenic edema (viable tissue) from irreversible venous infarction. ${ }^{8,9}$

Anticoagulation is considered the treatment of choice, even in the presence of hemorrhagic infarction. ${ }^{1,10-12}$ In a retrospective review of treatment outcome for DCVT, heparin or local 
A

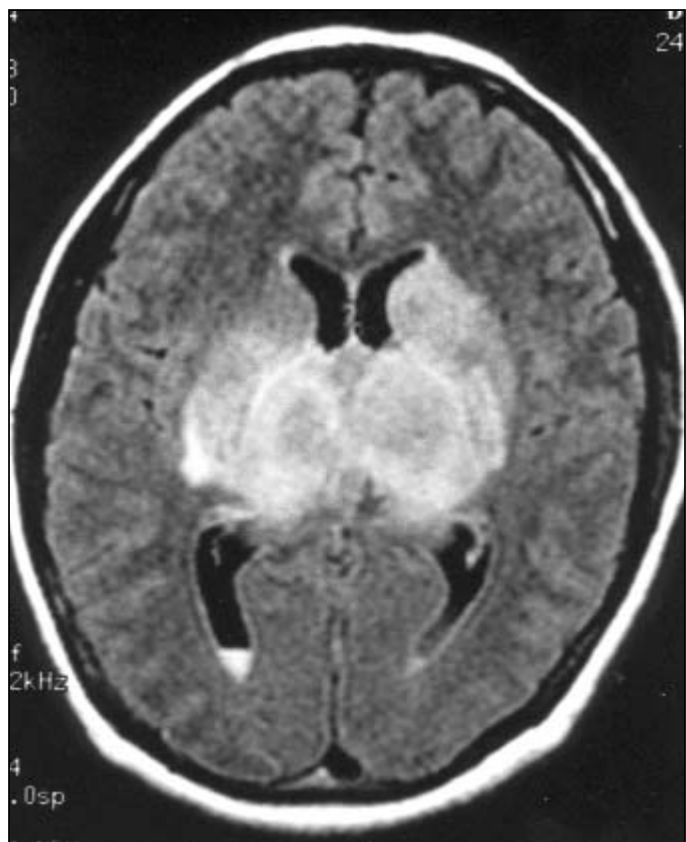

B

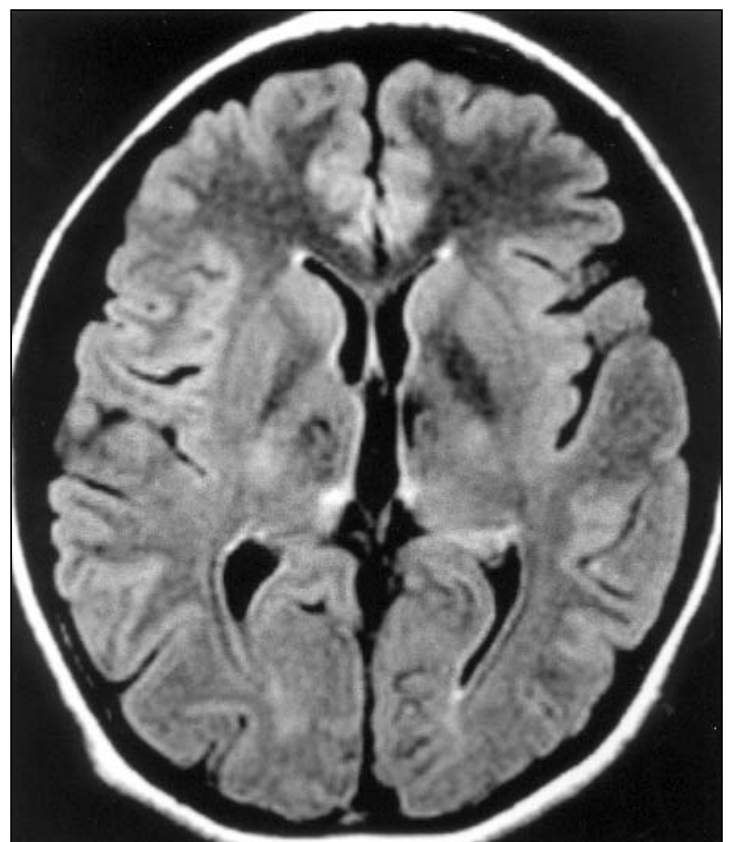

Figure 2: Axial brain MRI fluid-attenuated inversion-recovery (FLAIR) sequences.

(a) Initial scan showing abnormal hyperintensity in the thalamus bilaterally, extending into the basal ganglia. A fluid-fluid level is seen in the occipital horn of the right lateral ventricle, indicating intraventricular hemorrhage. Repeat scan two months later (not shown) showed a dramatic reduction in the hyperintensity, with two small residual foci of hyperintensity in the thalami. (b) Follow-up scan at 18 months post-stroke showing further resolution of the lesions, with two small residual foci of low signal intensity in the thalami suggesting infarction.

thrombolysis was associated with improved survival - mortality was $13 \%$ vs. $48 \%$ for "untreated" patients, despite similar initial severity and time to treatment in both groups. ${ }^{13}$ Most survivors had full recovery or only mild disability. Direct endovascular thrombolytic therapy is now being considered for patients who deteriorate despite adequate anticoagulation. ${ }^{13,14}$ Patients should be investigated for the underlying etiology of thrombosis, including newly recognized hereditary prothrombotic conditions. ${ }^{1,15,16}$

This case emphasizes that DCVT can produce extensive venous congestion and vasogenic edema without early infarction $^{17}$ and demonstrates that excellent clinical recovery from DCVT is possible, even with a profound deficit persisting for several weeks.

\section{ACKNOWLEDGEMENT}

The authors thank Dr. Cheryl Jaigobin for assisting in patient followup and Dr. Sandra Black for reviewing the manuscript. This paper was the winner of the 2000 "Consults in Stroke" Case Study Competition, sponsored by the Canadian Stroke Society, Canadian Stroke Consortium, Canadian Heart and Stroke Foundation, and AstraZeneca.

\section{REFERENCES}

1. Bousser MG, Barnett HJM. Cerebral venous thrombosis. In: Barnett HJM, Mohr JP, Stein BM, Yatsu FM, eds. Stroke: pathophysiology, diagnosis, and management. 3rd Ed. Philadelphia: Churchill Livingstone, 1998: 623-648.

2. Crawford SC, Digre KB, Palmer CA, Bell DA, Osborn AG. Thrombosis of the deep venous drainage of the brain in adults: analysis of seven cases with review of the literature. Arch Neurol 1995; 52: 1101-1108.

3. Baumgartner RW, Landis T. Venous thalamic infarction. Cerebrovasc Dis 1992; 2: 353-358.

4. Murray BJ, Llinas R, Caplan LR, Scammell T, Pascual-Leone A. Cerebral deep venous thrombosis presenting as acute micrographia and hypophonia. Neurology 2000; 54: 751-753.

5. Kim KS, Walczak TS. Computed tomography of deep cerebral venous thrombosis. J Comput Assist Tomogr 1986; 10(3): 386-390

6. Lafitte F, Boukobza M, Guichard JP, et al. Deep cerebral venous thrombosis: imaging in eight cases. Neuroradiology 1999; 41(6): 410-418.

7. Bell DA, Davis WL, Osborn AG, Harnsberger HR. Bithalamic hyperintensity on T2-weighted MR: vascular causes and evaluation with MR angiography. Am J Neuroradiol 1994; 15: 893-899.

8. Keller E, Flacke S, Urbach H, Schild HH. Diffusion- and perfusionweighted magnetic resonance imaging in deep cerebral venous thrombosis. Stroke 1999; 30(5): 1144-1146.

9. Hsu LC, Lirng JF, Fuh JL, et al. Proton magnetic resonance spectroscopy in deep cerebral venous thrombosis. Clin Neurol Neurosurg 1998; 100: 27-30.

10. Bousser MG. Cerebral venous thrombosis: nothing, heparin, or local thrombolysis? Stroke 1999; 30: 481-483.

11. Einhaupl KM, Villringer A, Meister W, et al. Heparin treatment in sinus venous thrombosis. Lancet 1991; 338: 597-600.

12. De Bruijn SFTM, Stam J, for the Cerebral Venous Sinus Thrombosis Group. Randomized, placebo-controlled trial of anticoagulant treatment with low-molecular-weight heparin for cerebral sinus thrombosis. Stroke 1999; 30: 484-488.

13. Smith AG, Cornblath WT, Deveikis JP. Local thrombolytic therapy in deep cerebral venous thrombosis. Neurology 1997; 48: 1613-1619. 
14. Frey JL, Muro GJ, McDougall CG, Dean BL, Jahnke HK. Cerebral venous thrombosis: combined intrathrombus rtPA and intravenous heparin. Stroke 1999; 30: 489-494.

15. Martinelli I, Sacchi E, Landi G, et al. High risk of cerebral-vein thrombosis in carriers of a prothrombin-gene mutation and in users of oral contraceptives. N Engl J Med 1998; 338: 1793-1797.

16. De Bruijn SFTM, Stam J, Koopman MMW, Vanderbroucke JP, for the Cerebral Venous Sinus Thrombosis Study Group. Casecontrol study of risk of cerebral sinus thrombosis in oral contraceptive users who are carriers of hereditary prothrombotic conditions. Br Med J 1998; 316: 589-592.

17. Haley EC, Brashear HR, Barth JT, Cail WS, Kassell NF. Deep cerebral venous thrombosis: clinical, neuroradiological, and neuropsychological correlates. Arch Neurol 1989; 46: 337-340. 